have been helpful to have comparisons drawn with other settings that did or did not show the same reciprocal age expectations (the British communist party or the legal profession perhaps?). This problem is connected to the method and the perspective it offers, which purports to be an in-depth 'naturalistic' account. Yet the author's perspective is present. I would have preferred an explicit account of where the author was coming from. We are told the Methodist Church is an extravagant bureaucratic structure: the logic of its structure seems to lie in tying its members up in a set of tasks that prevent them taking an active part (other than wage labour) in society outside of the church. But Jerrome tells only of the benefits of this process - the relative privilege of older people within the church society-without mentioning any disadvantages.

Department of Health and Social Welfare, The Open University, Buckinghamshire

\title{
Education and Older Adults
}

\section{Frank Glendenning}

K. Warner Schaie, The hazards of cognitive aging. The Gerontologist, 29, 4 (I 989), 484-93.

For some years, American psychologists have been commenting on the emerging results from their numerous longitudinal studies which involve older people (one of which goes back to the late i920s). One of the best known is the Seattle Longitudinal Study (SLS), begun in 1956 as Schaie's doctoral dissertation. Seeking to understand why some individual's retain their behavioural competence well into advanced old age, whereas others show early decline, the research has followed the development of mental abilities from young adulthood to old age. A database has been developed from five test cycles (1956, I963, 1970, I 977,1984 ) and there have been several collateral studies. The 1956 sampling frame comprised approximately 18,000 potential adult subjects. By 1984 , the potential numbers had swelled to 219,000 . The original sample of 500 (from a health maintenance organization (HMO) in Seattle) had shrunk to 97 by 1984 . But each seven years, all accessible previous subjects were retested and new subject panels were randomly selected from the parent population. The particular HMO involved blue- and white-collar workers, craftsmen, service workers and all levels of professionals [sic]. Between 1956 and i 984 , nearly three 
and a half thousand subjects were involved in the study and by 1984 (including the new subject panel), there were $\mathrm{I}, 44^{8}$ still involved.

The principal variables, according to Schaie, were measures of the primary mental abilities of verbal meaning, space, reasoning, number and word fluency, already identified by Thurstone in the late r 930 as variables accounting for the major proportion of individual differences for children and adolescents and adapted for use with older adults by Schaie in the 1970 os. $^{1}$ Attention was also paid to behavioural rigidity, the collection of all personal data about the subjects, including lifelong educational pursuits, and health histories. Schaie defines the measures used in the paper. The research has focused on five questions.

I. Does intelligence change uniformly through adulthood or are there different life-course ability patterns?

No uniform pattern of age-related changes was found. The data lends 'some support to the notion that active or fluid abilities' (which reflect the quality of one's brain) 'tend to decline earlier than passive or crystallised abilities' (mental abilities that depend upon experience and education in the broad sense). Gender difference trends suggest that women may decline earlier on the active abilities, while men do so on the passive abilities. 'Moreover, while fluid abilities begin to decline earlier, crystallized abilities appear to show steeper decrement once the late seventies are reached.'

2. At what age is there a reliably detectable age decrement in ability and what is the magnitude of that decrement?

Data collected up to the 1970 cycle suggested that this could not be demonstrated before the age of 60 years, but it may be found for all abilities by age 74. Analyses from the two most recent cycles suggest that a statistically significant average decrement can be found for some, but not all cohorts, among people in their fifties. More detailed analyses of differences in intellectual change demonstrate that even at $8 \mathrm{I}$ years, less than half of all observed individuals have shown reliable decremental change over the preceding seven years. 'Maintenance of functioning on one or more abilities is characteristic for most individuals well into advanced old age.'

3. What are the patterns of generational differences and what is their magnitude?

SLS results have 'conclusively demonstrated the prevalence of substantial generational (cohort) differences in psychometric abilities'. There has been an 'almost linear positive cohort shift for inductive 


\section{$34^{8} \quad$ Frank Glendenning}

reasoning, with more spasmodic positive shifts for verbal meaning and spatial orientation'. A further finding shows that there is a curvilinear cohort pattern for number skills. These peak with the 1917 and 1924 birth cohorts and then show a negative slope. Word fluency demonstrates a curvilinear pattern also, the peaks being in the 1889 and I 959 birth cohorts and the lowest in the cohort of I93I. Schaie concludes from this that cross-sectional studies have underestimated age changes before age 60 years for those variables with negative cohort gradients and over-estimated age changes for those variables with positive gradients.

4. What accounts for individual differences in age-related change in adulthood?

Longitudinal data enables individual differences to be investigated. As a result of the study of SLS data, Schaie has predicted favourable cognitive ageing as a result of such variables as the absence of cardiovascular and other chronic disease, favourable environment, involvement in a complex and intellectually stimulating environment, flexible personality style in mid-life, high cognitive status of spouse, and maintenance of level of perceptual processing speed.

5. Can cognitive decline in old age be reversed?

As a result of tracking stability or decline through longitudinal studies, it has been shown possible for interventions to remedy intellectual decline and for cohort differences to be reduced. Observed decline in older people living in residential settings may well result from disuse and is clearly reversible for many. Two-thirds of the experimental subjects showed improvement through stimulation and exercise and $40 \%$ of those who had declined over i 4 years were restored to their predecline level.

At the time of the publication of this paper, a considerable amount of Schaie's detailed and recent findings were still at the printers, but the titles are among some two dozen personal citations.

In the second half of the paper, Schaie proceeds to demonstrate that it is now possible to predict the most likely age of an individual when significant cognitive decline will occur. Asserting that changes occur in a linear or sometimes more complex continuous form, he goes on to suggest that changes which occur suddenly are in response to 'abrupt or cumulative insults that reach a threshold value', and that eventhistory analysis (based on a longitudinal record of when events happen) may be of considerable assistance in tracing and under- 
standing the reasons for the change or disjunctive shift. He refers to the importance of Allison's work in this respect and explains the process by which he predicts the average expected age of decline. ${ }^{2} \mathrm{He}$ concludes by saying that 'cognitive ageing is not a uniform phenomenon, but is highly differentiated across abilities. (It) occurs at differential rates depending upon a variety of demographic and other personal characteristics'. He also believes importantly that the introduction of new methodologies, such as event-history analysis, may lead to a paradigm shift for theorising in the behavioural study of ageing.

\section{Comment}

Although the detailed scope of this paper is outside the present writer's professional competence, it is included here because the continuing findings of Schaie and others are highly relevant to the concerns of educational gerontologists. With popular opinion still suffering from the crude results of early cross-sectional studies of ageing, research results based on the analyses of longitudinal data are of deep interest. For lacking up to now have been the research results to match the popular belief on both sides of the Atlantic that education in later life can be one of the effective intervention strategies in arresting cognitive decline. We have learnt much from life-span developmental psychologists in America, Australia and Europe over the last quarter of a century. Schaie's personal contribution now stretches over thirty years. One of the current challenges that faces the development of educational gerontology is the number of conflicting messages that we receive from psychologists about cognition and ageing. There is perhaps sufficient information now for someone to write a comparative study of the current state of the art.

\section{NOTES}

I Allison, P. D. Event History Analysis : Regression for Longitudinal Event Data, Sage, Beverly Hills, 1984 .

2 Thurstone, L. L. Primary Mental Abilities. University of Chicago Press, Chicago, 1938.

Du Zicai and Liu Pingsheng, The Principles Governing Education for Aged People in China, Wuhan, China, I 989.

The contents of this paper, originally delivered at the meeting at the International Congress of Gerontology at Acapulco in June 1989, 
deserve to be communicated to a wider audience. The original title was, 'Research into the laws governing education for aged people in China'. The present writer has replaced it with the above title for the sake of clarity. The issue of an ageing society began to be discussed seriously in China in the early 1980 . Life expectancy had doubled to 70 years in 40 years. The last census (n.d.) showed that 91 million people were by then aged over 60 and the problem to be faced was how 'they can spend their late years in a way meaningful both the themselves and society'.

The nuclear family is increasing, assert the authors, especially in the cities. In Wuhan, for instance, $43 \%$ of older people live away from their family. Until 1982 , all vowed to work for the whole of their life for the sake of the community. When this system came to an end in 1982 , the retirement age was established as 60 years for a man and 55 for a woman. Those who draw a state pension live mainly in the cities, claim the authors, the pension amounting to $75 \%$ of their wage while in fulltime work. Many could not afford to go to school when they were young and now express 'a crying need for something to do and to learn'. This, say the authors, applies especially to those with secure incomes. However, even they require some financial assistance to meet their student fees.

New educational legislation in 1979 led a few years later to the setting up of schools and universities for older people. It was estimated in 1988 that there were 916 such institutions in operation throughout mainland China (excluding Tibet, Qinhai and Hainan provinces), with I 30,000 enrolments. These universities and schools are spread over 27 provinces and they have already formed a network of their own which, the authors believe, fills a gap in China's educational system as a whole. The majority of those attending these universities and schools for older people are retired. They are divided into two categories. The first are veterans who had involved themselves in the revolution before the founding of the People's Republic of China in 1949. The second includes those who began to work for New China after October 1949. These are mainly retired executives, intellectuals and workers, who have been honourably discharged from army or government service. In Wuhan, retired veterans attending universities or schools amount to $1.2 \%$ of the elderly population, ordinary retired executives $11.7 \%$, and retired workers $65.7 \%$. The authors observe that it is the retired veterans who are most eager to attend.

The purpose of education for older people in China is 'to broaden (their) knowledge, influence health and character building', to be like 'old steeds in the stable aspiring to gallop a thousand li'. Courses offered cover a wide range: calligraphy, horticulture, sanitation, health 
care, painting, language, literature, physical education, domestic science, history, political science, current affairs, photography, law, geography, applied science, law and English language. Funding and sponsorship for these universities and schools is normally by the local communist party, the Red Cross, local societies for the aged or universities. A few are funded by local government. Some hold large classes, some small classes. Some have long-term programmes, some short-term. Teaching hours range from 2 to 8 hours a week and some courses have examinations, while some rely on continuous assessment. Accommodation is frequently inadequate. Currently, these universities and schools for older people are administered and controlled by older people themselves, although the intention is to move towards an intergenerational system. Wuhan University for the Aged has a staff of 142, among whom retired people constitute $83 \%$. The remainder tend to be drawn from those currently teaching in local universities or colleges.

As elsewhere in the world, the authors report an improvement in health and well-being of those who participate and a consequent raising of the profile of older people in society. Retraining for older workers is encouraged. Established farmers, as well as peasant farmers, are taking advantage of enrolment for relevant studies. The movement is still at an experimental stage. There has been rapid growth and there is a shortage of funds. Many universities and schools for older people recognise that they cannot at present meet the demand for learning opportunities. The authors plead for the provision of a suitable environment, recognised terms and semesters, more appropriate courses, tutor training, better management and look forward to an educational system in China that embraces the concept of true life-long education.

\section{Comment}

This will find echoes worldwide, as in so many societies we struggle with the marginalisation of older people and their educational requirements. The paper does not include any references or evidence of primary research, although surveys are mentioned. It is to be hoped that the vigour of this movement in the People's Republic of China and the recent UNESCO Conference in November 1989 at Wuhan University for the Aged will lead to an increasing international exchange of information and research findings, which will benefit educational gerontology worldwide.

Centre for Social Gerontology,

University of Keele 